\title{
Discussion on the method of overhead insulated conductor with connecting ground wire
}

\author{
Chuang Wang ${ }^{1}$, Guobin Liu ${ }^{1}$, Xiao Liu $^{1}$, Xue Wang ${ }^{1}$, Hui Tang ${ }^{1}$, Jiatian Bai ${ }^{1}$, \\ Wenfeng $\mathrm{Hao}^{1}$, Chuanzong Zhao ${ }^{1}$, Xue Bai ${ }^{2}$, Hainan $\mathrm{Su}^{3}$ \\ ${ }^{1}$ Fushun Power Supply Company, Liaoning Electric Power Company Limited, State Grid, China \\ ${ }^{2}$ Huludao Power Supply Company, Liaoning Electric Power Company Limited, State Grid, China \\ ${ }^{3}$ Dandong Power Supply Company, Liaoning Electric Power Company Limited, State Grid, China
}

Keywords: overhead insulated conductor; special acupuncture grounding device; personal feeling electricity; electrical inspection ground ring; lightning protection electrical inspection ground ring

\begin{abstract}
Insulation and corrosion performance of $10 \mathrm{kV}$ overhead insulated conductor is better than that of ordinary overhead bare conductor, it can avoid trees, kites, wires and the strong wind causing interphase short circuit and grounding accident, so as to effectively solve line tree contradiction and line failure caused by external damage, and greatly improve the power supply reliability of lines (grid). Overhead insulated conductor can't ground wire, and can only install inspection ground ring or lightning protection electrical inspection ground ring in advance. This method leaves hidden danger to safe operation of overhead insulated conductor, and causes overhead insulated conductor watering and reduces the tensile force. Developed special acupuncture grounding device of overhead insulated conductor successfully solves the problems of inspection and grounding wire at the workplace.
\end{abstract}

\section{Introduction}

In recent years, as the continuous expansion of China's urban power grid, the rapid growth of power load, and improving the reliability of power supply, more and more urban and rural distribution network greatly adopts overhead insulated conductor. Insulation and corrosion performance of $10 \mathrm{kV}$ overhead insulated conductor is better than that of ordinary overhead bare conductor, it can avoid trees, kites, wires and the strong wind causing interphase short circuit and grounding accident, so as to effectively solve line tree contradiction and line failure caused by external damage, and greatly improve the power supply reliability of lines (grid). It is cheaper than buried cable, its construction is simple, and maintain is convenient. Thus it has been widely used in urban and rural distribution network, and improves the distribution network insulation. ${ }^{[2]}$

When workers are working on all or part of the power lines that have been cut off, power failure, power inspection, grounding wire are three important technical measures that ensures the safety of power line construction workers. 《Power safety regulations》(power line section) fifty-ninth provisions: 1. After verifying no voltage on lines, each working class (group) grounds wire immediately at both ends of the working area; 2. It is possible to send power to the power line of the branch line, they must hang grounding wire; 3 . If there is an induced voltage in the power line, they must hang grounding wire. ${ }^{[4]}$

\section{Significance of grounding wire at work place}

After power line outage, there are several sudden incoming cases:

(1) In the crossing place, the other live line breaks into connect to a power outage line.

(2) Misoperation causing Mistakenly power of a power outage line.

(3) User owned power plant backs to power system falsely.

(4) When the main power supply fails due to line for dual power user, and backup power supply. Locking failure or misoperation backs to power system.

(5)Temporary external low voltage power supply falsely sends to high voltage side by 
transformer.

(6) Voltage transformer backs to power supply failure equipments.

(7) Crossing or parallel lines cause inductive power.

(8) Distant thunder causes power failure line with power.

So, in order to prevent the above situations from endanger the safety of the line staff, it is possible to transmit power to the side of the power transmission line or there is inductive voltage on the power line, you must grounding wire. ${ }^{[3]}$

\section{Grounding method of overhead insulated conductor at present}

Generally people use overhead insulated wire to lay in the middle and low voltage line of urban distribution network (10kV and below voltage level), while you repair line or equipment, in order to ensure the safety of maintenance personnel, you should ground protection wire after verifying the line without power. When you ground wire, ground clamp and wire (overhead insulated wire core) should be reliable contact. Insulated wire can't hang, so you can use various electrical inspection ground ring. There are: 1. electrical inspection ground ring; 2. lightning protection electrical inspection ground ring.

\section{Electrical inspection ground ring}

There are electrical inspection ground ring of overhead insulated conductor at present (BYD series), it is shown in Fig.1.

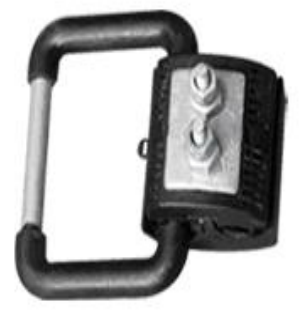

BYD -0

electrical inspection ground ring

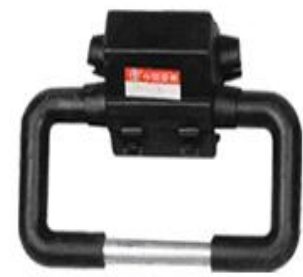

BYD -1

electrical inspection ground ring

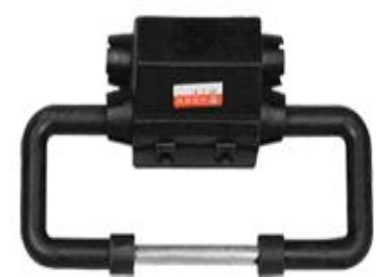

BYD -2

electrical inspection ground ring

Fig.1 electrical inspection ground ring (BYD series)

\section{Lightning protection electrical inspection ground ring}

Lightning protection electrical inspection ground ring can prevent overhead insulated conductor from lightning break, inspect power in maintenance and become temporary grounding protection device, it is shown in Fig.2.

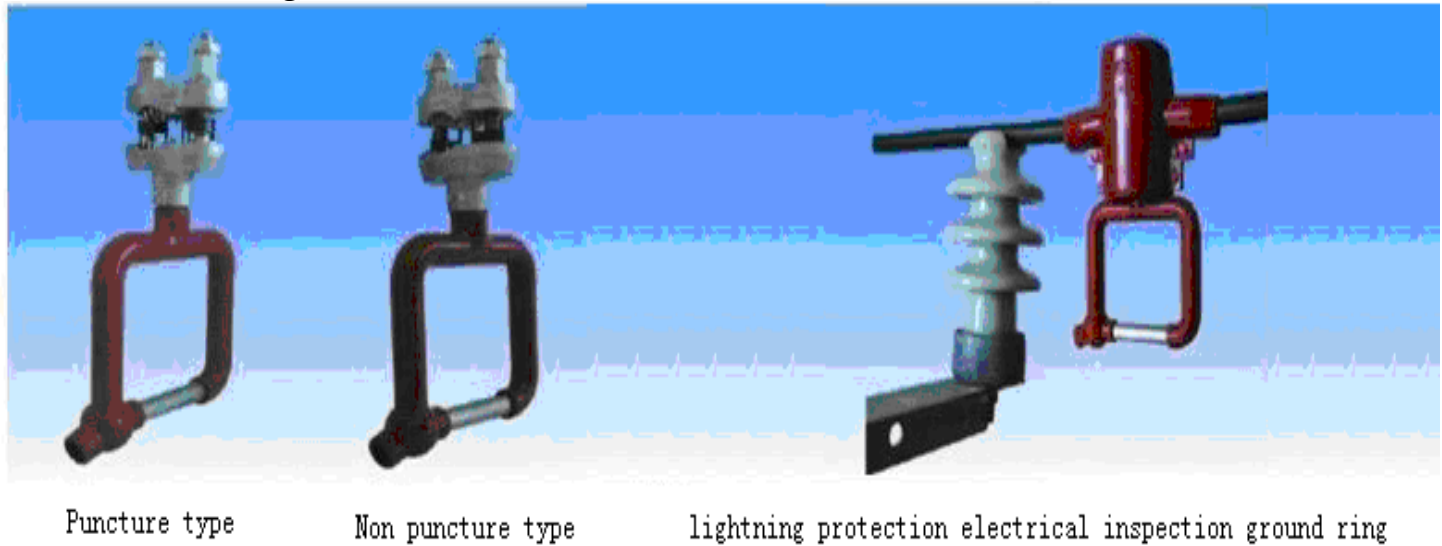

Fig.2 lightning protection electrical inspection ground ring (FDL series) 
FDL type is a kind of load side installed on line insulator, it is designed to prevent $10 \sim 20 \mathrm{kV}$ overhead insulated wire lightning break as well as for the inspecting power in maintenance and the grounding device combo products. At present, the insulated conductors are widely used in overhead lines 10 to $20 \mathrm{kV}$ and below, but there are insulated overhead line lightning protection level of the congenitally deficient (struck by lightning). When lightning strikes, arc rod and insulator metal parts discharge each other, it makes the power frequency continuation of the arc moving to the ignition rod burning, so the insulated conductor isn't damaged. When you work, it can inspect power in maintenance and become temporary grounding protection device.

\section{The malpractice of installing electrical inspection ground ring}

Grounding wire is the most reliable technical measures that prevents sudden incoming power and protects the line construction personnel from avoiding power shock, but someone works on the overhead insulated distribution line after blackout, there are problems for partial units that just grounds wire. Surface of overhead insulated wire has cross-linking polyethylene insulation layer of nominal thickness that is $3.4 \mathrm{~mm}$ (nominal insulation thickness of thin insulation is $2.5 \mathrm{~mm}$ ). Because these units didn't set aside the power outage at the work site, builders usually hang the grounding wire on the bare wire clip or use the electrician knife to cut out insulation layer of the overhead insulated wire, and ground wire, this illegal practice brings significant security risks.

In order to ground wire for overhead insulated conductors, you can adopt installing electrical inspection ground ring(or lightning protection electrical inspection ground ring)in certain parts of overhead insulated conductors. Although this method solves the problem of overhead insulated conductor grounding wire, it gives the safe operation of overhead insulated wire to leave two main risks. ${ }^{[1]}$

Firstly, insulated conductor is affected with damp by water inflow easily, its structure and installation conditions are easy to water and no volatile. When the insulating layer is broken, water enters the aluminum wire through effect of capillary suction and gathers in the lower part of the sag. Because environmental pollution water is acidic, it reacts with aluminum to produce white powder. This kind of oxide accelerates the corrosion of the wire under the electric field, reduces wire radian, appears bulging phenomenon, even breaks wire, and shortens the life of the wire.

Secondly, breaking force reduces, and tractive force of overhead insulated conductor is conductor and insulation joint commitment, insulation layer is destroyed, insulating layer loses traction, all the weights are borne by the wire core. When you install electrical inspection ground ring and lightning protection electrical inspection ground ring, due to excessive pressure, it leads wire deformation, even broken strands, greatly reduces the tensile force of insulated overhead conductor. There are several broken line accidents in the large wind (windy) and heavy covered areas.

\section{Development of special grounding device}

\section{Device physical map}

Using electrical inspection ground ring and lightning protection electrical inspection ground ring to leave two hidden dangers for overhead insulated conductor, so development of acupuncture grounding device can solve the problem that the overhead insulated conductor is not easy to hang the ground wire. Figure 3 is a complete set of physical devices. 


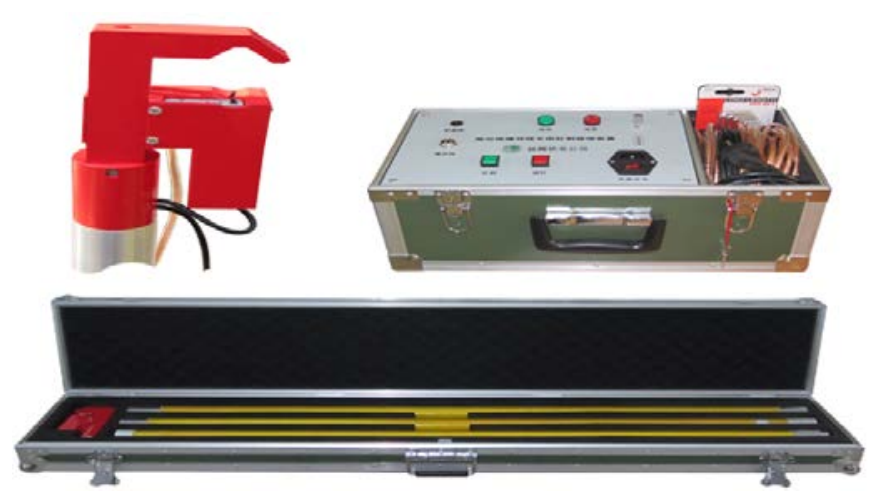

\section{Working principle}

Figure.3 acupuncture grounding device physical map

Select the appropriate location near the workplace, use insulating rod to put electric acupuncture apparatus with ground wire to install on insulated conductors. Start forward control button, puncture the wire through the insulating layer and contact conductor well. Acupuncture section spin up on the slide track. Firstly, it can contact insulation sheath. Secondly, pierce the insulating layer. When the needle penetrates the insulating layer, and contact conductor, the outer layer of the insulation will touch the limiting button near the needle, then the machine will stop in this position. If the red light flashes on the host, the results show that the line grounding effect is not good, If the green light flashes on the host, the results show that the line grounding effect is good. Connecting closing button shows that grounding wire and earth connect each other. If grounding is good, the indicator tweets and shines; if grounding isn't good, the indicator doesn't react, it is shown in Fig.4. ${ }^{\text {[5] }}$

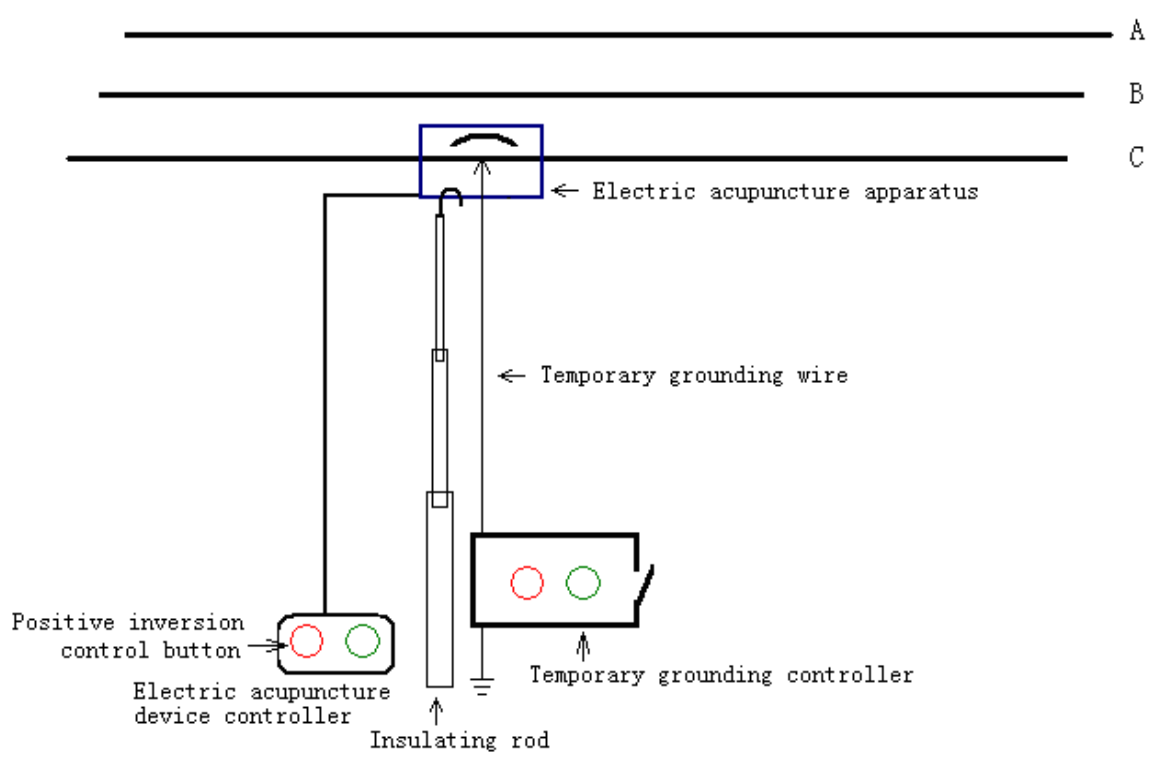

Figure.4 acupuncture grounding device simulation diagram

\section{Laboratory inspection and acceptance}

Fig. 5 is shown in the following. 

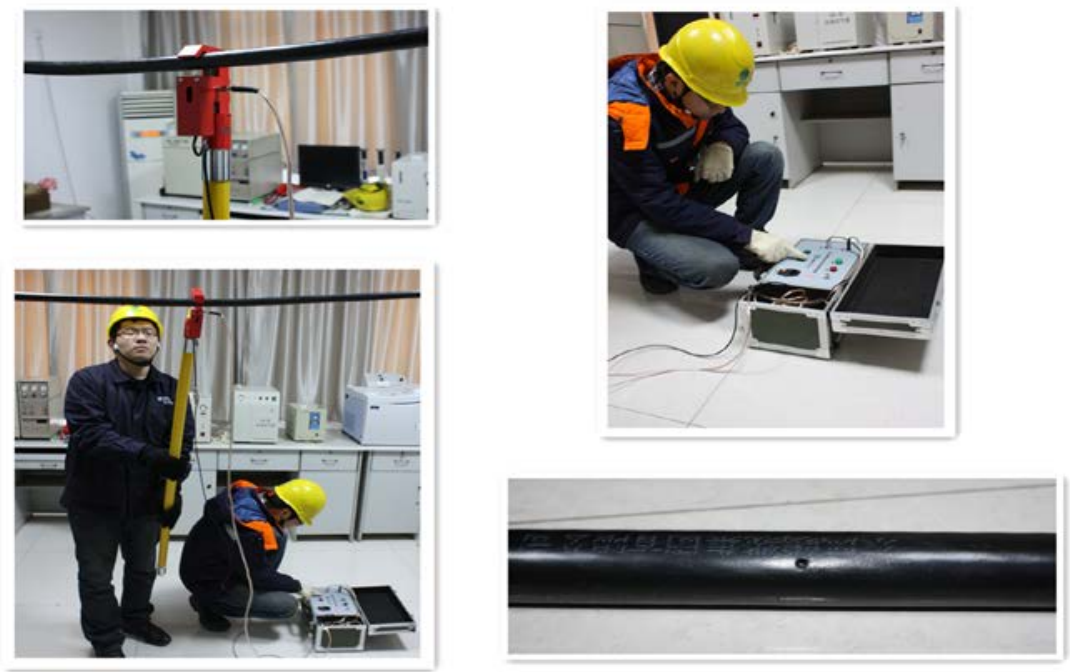

\section{Field application}

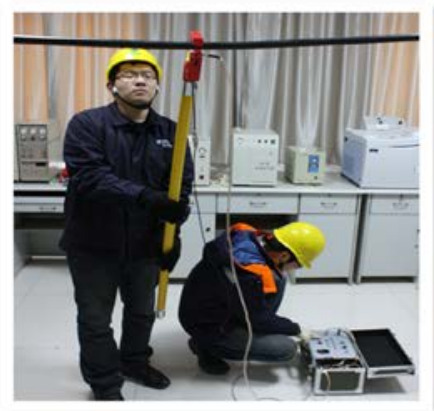

Figure.5 Laboratory inspection and acceptance work

Special acupuncture grounding device of overhead insulated conductor is widely used in practical work. For example, Taiqing Yixian, Chuntai Erxian, Jiangbei Ganxian, Youzhan Ganxian. it is shown in Fig.6.
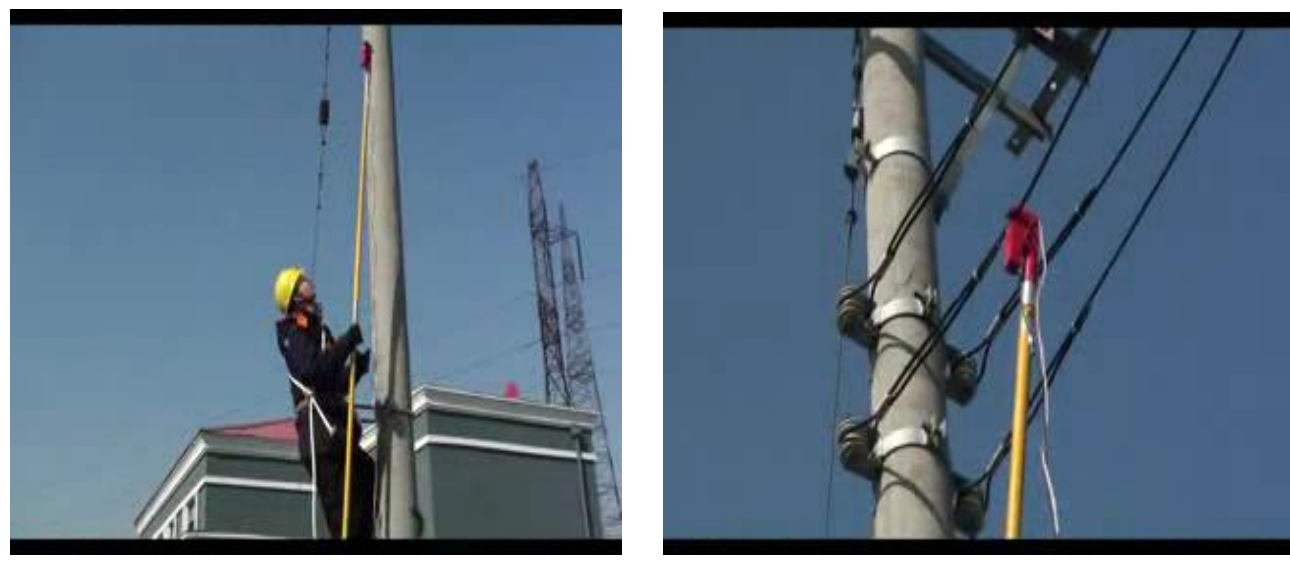

Figure.6 Field operation

Note: Small hole of overhead insulated conductor drill uses plasticine to plug it, then wraps around a layer of high pressure waterproof tape, the plugging effect is good.

\section{Conclusions}

Special acupuncture grounding device of overhead insulated conductor performance meets the actual needs, operation is easy, it is applicable for 35-240 model overhead insulated conductor. Induction voltage reduces to about $20 \mathrm{~V}$, and achieves the desired objectives. In order to consolidate results, and improve technical measures, organizes 《special acupuncture grounding device of overhead insulated conductor》, the device is also identified by the scientific and technological achievements of Liaoning Electric Power Company Limited, State Grid, Won the national invention and utility model patents. The device has reached the domestic advanced level, and owns popularization and application.

\section{References}

[1] Weijiang Chen, Qingfeng Li, Xiaokang Lai. 10kV overhead insulated conductor lightning protection wire arc fitting research [J]. Grid technology, 2002,26(9):25-29

[2] Weijiang Chen, Zhaoying Sun, Xiaogang Wang, Arc protection hardware and clamping 
insulation power frequency arc test conditions in the $10 \mathrm{kV}$ overhead line [J]. Grid technology, 2005,29(17):5-7.

[3] Zhenzhang Xie. Application of overhead insulated conductor is in the rural area [J]. Rural Electrician , 2006, (7) :25-26.

[4] Xuyi Lin. Application and precautions of overhead insulated conductors in $10 \mathrm{kV}$ distribution network[J]. Sichuan electric power technology,2005,(2) :29-31.

[5] He Li. Discussion on the new technology of insulation wire connection in distribution network[J]. Low voltage electrical apparatus,2011(21):50-53. 